\title{
CRISPR 2 PCR and high resolution melting profiling for identification and characterization of clinically-relevant Salmonella enterica subsp. enterica
}

\author{
Nuttachat Wisittipanit ${ }^{\text {Equal first author, } 1 \text {, Chaiwat Pulsrikarn }}{ }^{2}$, Sudarat Srisong ${ }^{3}$, Rungthiwa Srimora ${ }^{3}$, Nattinee Kittiwan \\ 4 , Kritchai Poonchareon ${ }^{\text {Corresp. Equal first author, } 5}$ \\ ${ }^{1}$ Department of Material Engineering, School of Science, Mae Fah Luang University, Chiang Rai, Thailand \\ 2 \\ 2 Department of Medical Sciences, WHO National Salmonella and Shigella Center, National Institute of Health, Ministry of Public Health, Nonthaburi, \\ Thailand \\ 3 Division of Biochemistry, School of Medical Sciences, University of Phayao, Phayao, Thailand \\ 4 Veterinary Diagnostic Center, Veterinary Research and Development Center (Upper Northern Region), Lampang, Thailand \\ 5 Division of Biochemistry, School of Medical Sciences, The University of Phayao, Phayao, Thailand \\ Corresponding Author: Kritchai Poonchareon \\ Email address: kof_of@hotmail.com
}

Background: Nontyphoidal Salmonella spp. constitute a major bacterial cause of food poisoning. Each Salmonella serotype causes distinct virulence to humans.

Method: A small cohort study was conducted to characterize several aspects of Salmonella isolates obtained from stool of diarrheal patients $(n=26)$ admitted to Phayao Ram Hospital, Phayao province, Thailand. A simple CRISPR 2 molecular analysis was developed to rapidly type Salmonella isolates employing both uniplex and high resolution melting (HRM) curve analysis.

Results: CRISPR 2 monoplex PCR generated a single Salmonella serotype-specific amplicon, showing S. 4,5,12:i- with highest frequency (42\%), S. Enteritidis (15\%) and S. Stanley (11\%); S. Typhimurium was not detected. CRISPR 2 HRM-PCR allowed further classification of S. 4,5,12:i- isolates based on their specific CRISPR 2 signature sequences. Highest prevalence of Salmonella infection was during the summer season (April to August). Additional studies were conducted using standard multiplex HRM-PCR typing, which confirmed CRISPR 2 PCR results and, using a machine-learning algorithm, clustered the majority of serotypes into six clades; repetitive element-based (ERIC) PCR, which clustered the serotypes into three clades only; antibiogram profiling, which revealed majority resistant to ampicillin (73\%); and test for extended spectrum $\beta$-lactamase production (two isolates) and PCR-based detection of bla alleles.

Conclusion: CRISPR 2 PCR provided a simple assay for detection and identification of clinically-relevant Salmonella serotypes. In conjunction with antibiogram profiling and rapid assay for $\beta$-lactamase producers, this approach should facilitate detection and appropriate treatment of Salmonellosis in a local hospital setting. In addition, CRISPR 2 HRM-PCR profiling enabled clustering of S. S. 4,5,12:i- isolates according to CRISPR 2 locus signature sequences, indicative of their different evolutionary trajectories, thereby providing a powerful tool for future epidemiological studies of virulent Salmonella serotypes. 
1 CRISPR 2 PCR and high resolution melting profiling

2 for identification and characterization of clinically-

3 relevant Salmonella enterica subsp. enterica

4

5

6

7

8

9

10

11

12

13

14

15

16

17

18

22

23

24

25

26

27

28

29

30

31

32

33

34

35

36

37

38

Nuttachat Wisitipanit ${ }^{1}$, Chaiwat Pulsrikarn ${ }^{2}$, Sudarat Srisong ${ }^{3}$, Rungthiwa Srimora ${ }^{3}$,Nattinee Kittiwan $^{4}$, Kritchai Poonchareon ${ }^{3}$

${ }^{1}$ Department of Material Engineering, School of Science, Mae Fah Luang University, Chiang Rai, Thailand

${ }^{2}$ Department of Medical Sciences, WHO National Salmonella and Shigella Center, National Institute of Health, Ministry of Public Health, Nonthaburi, Thailand

${ }^{3}$ Division of Biochemistry, School of Medical Sciences, University of Phayao, Phayao, Thailand

${ }^{4}$ Veterinary Research and Development Center (Upper Northern Region), Hang Chat, Lampang, 52190, Thailand.

Corresponding Author:

Kritchai Poonchareon

19 Moo 2, Tambon Maeka, Amphur Muang, Phayao, 56000, Thailand

Email address: kof_of@hotmail.com

\section{Abstract}

Background: Nontyphoidal Salmonella spp. constitute a major bacterial cause of food poisoning. Each Salmonella serotype causes distinct virulence to humans.

Method: A small cohort study was conducted to characterize several aspects of Salmonella isolates obtained from stool of diarrheal patients $(n=26)$ admitted to Phayao Ram Hospital, Phayao province, Thailand. A simple CRISPR 2 molecular analysis was developed to rapidly type Salmonella isolates employing both uniplex and high resolution melting (HRM) curve analysis.

Results: CRISPR 2 monoplex PCR generated a single Salmonella serotype-specific amplicon, showing $S .4,5,12: \mathrm{i}-$ with highest frequency (42\%), $S$. Enteritidis (15\%) and $S$. Stanley (11\%); $S$. Typhimurium was not detected. CRISPR 2 HRM-PCR allowed further classification of $S$. 4,5,12:i- isolates based on their specific CRISPR 2 signature sequences. Highest prevalence of Salmonella infection was during the summer season (April to August). Additional studies were conducted using standard multiplex HRM-PCR typing, which confirmed CRISPR 2 PCR results and, using a machine-learning algorithm, clustered the majority of serotypes into six clades; 
repetitive element-based (ERIC) PCR, which clustered the serotypes into three clades only; antibiogram profiling, which revealed majority resistant to ampicillin (73\%); and test for extended spectrum $\beta$-lactamase production (two isolates) and PCR-based detection of bla alleles. Conclusion: CRISPR 2 PCR provided a simple assay for detection and identification of clinically-relevant Salmonella serotypes. In conjunction with antibiogram profiling and rapid assay for $\beta$-lactamase producers, this approach should facilitate detection and appropriate treatment of Salmonellosis in a local hospital setting. In addition, CRISPR 2 HRM-PCR profiling enabled clustering of $S .4,5,12$ :i- isolates according to CRISPR 2 locus signature sequences, indicative of their different evolutionary trajectories, thereby providing a powerful tool for future epidemiological studies of virulent Salmonella serotypes.

\section{Introduction}

Salmonella enterica can cause human gastroenteritis owing to inadequate hygienic standards of living and/or consuming poorly prepared fresh food. $S$. enterica has been subtyped to more than 2,463 serovars according to their antigenic properties (Kauffman, 1972); however, only a limited number of serovars cause human infection (Uzzau et al., 2000) and, thus, identification of these serotypes is of public health importance. Distribution of Salmonella serovars is markedly different among continents (Galanis et al., 2006), but within a single country such as Thailand serovars slightly varies in different geographical regions, the most common clinical serovars being S. 4, 5, 12:i:-, Anatum, Derby, Enteritidis, and Weltevreden (Bangtrakulnonth et al., 2004) (Padungtod \& Kaneene, 2006).

Emergence of multi-drug resistance (MDR) in the major prevalent non-typhoidal Salmonella serovars found in human gastroenteritis is related to an acquisition of antibiotic-resistant genes especially in $S$. Typhimurium (Velge, Cloeckart \& Barrow, 2005). In Thailand, a significant increase in resistance to amikacin, kanamycin and second line antibiotic ceftriaxone is suggested to be related to over-use of antibiotics to livestock feed and in medical treatment (Boonmar et al., 1998). Also, an increase in resistance to quinolones such as nalidixic acid was reported (Sirsichote et al., 2010). Failure of treatment from third-generation cephalosporins, the extended spectrum $\beta$-lactamases (ESBLs), has created a major threat to treatment of MDR microbial pathogens and has stimulated studies on their epidemiology (Rupp \& Fey, 2003). ESBL genes, such as bla OXA, blaSHV, blaTEM and the more recent blaCTX-M, generate different levels of virulence and transmission capability (Ewers et al., 2012). ESBL $\beta$-lactemase CTX-M is of particular concern due to its global dissemination through both clonal and horizontal gene transfer (Cantón, González-Alba \& Galán, 2012).

The standard method for Salmonella identification is based on a culture method (ISO 6579:2000, 2002). The assay uses different selective media, followed by serotyping based on various combinations of $\mathrm{O}$ and $\mathrm{H}$ antigenic determinants (Kauffman, 1972). These methods require skilled personnel to perform the standardized protocols, which are laborious and timeconsuming. In order to reduce the turnover time for subtyping Salmonella spp., multiplex PCR of specific gene determinants was introduced, which depends on sequence polymorphisms of $r f b$ 
79 locus and flagellar alleles (Kim et al., 2006), (Masek et al., 2014). Other molecular modifications

80 such as high resolution melting temperature (HRM)-PCR assay has been coupled to multiplex

81 PCR for detection of polymorphisms of 16S rDNA (O'Regan et al., 2008), fljB, gyr B and $y c f \mathrm{Q}$

82 (Zeinzinger et al., 2012). HRM-PCR was applied to discriminate between two most prevalent

83 clinical serotypes, namely, $S$. Enteritidis and $S$. Typhimurium (Bratčikov \& Mauricas, 2009).

84

85 Clustered regularly interspaced short palindromic repeats (CRISPR) were discovered as a new

86 family of repeated DNA sequences in many prokaryotes (Jansen et al., 2002). Their genetic

87 signatures are characterized by repeated patterns of DNA, known as direct repeats (DRs), 24-47

88 bp in length, and DNA variable sequences (spacers) of 21-72 bp (Shariat \& Dudley, 2014).

89 Adjacent to the CRISPR locus are a "leader sequence"' and cas (CRISPR-associated sequence)

90 gene (Horvath \& Barrangou, 2010). Salmonella spp. harbor two different CRISPR loci, namely,

91 CRISPR 1 and CRISPR 2 that correlate with Salmonella serotype and multilocus sequence type

92 (Fabre et al., 2012). Characterization of CRISPR alleles provide information of spacer content

93 for performing Salmonella typing and subtyping (Fabre et al., 2012), (Liu et al., 2011). CRISPR

94 typing was recently applied to identify virulent Salmonella infection of chicken raised in a single

95 farm as well as in farms from different areas (Fei et al., 2017), (Li et al., 2018). More recently,

96 CRISPR loci polymorphisms were utilized in a single-step assay to identify multiple Salmonella

97 spp. contamination of a poultry sample (Thompson et al., 2018).

98 In order to reduce operational cost and turnover time of the traditional culture assay for detecting

99 and serotyping Salmonella spp., a simple CRISPR 2-based conventional and monoplex HRM-

100 PCR was developed in conjunction with HRM triplex and a novel machine-learning algorithm

101 tool to analyze and identify Salmonella serotypes in correlation with repetitive element-based

102 (ERIC)-PCR genotyping and a rapid ESBL test, and, in addition, to distinguish S. 4,5,12:i-

103 isolates from different epidemiological settings.

104

105

106

107

108

109

110

111

112

113

114

115

116

\section{Materials \& Methods}

1. Isolation and identification of Salmonella in stool of diarrheal patients

Stool samples were collected from patients $(n=26)$ with diarrhea during May 2016 to July 2017

at Phayao Ram Hospital, Phayao province, Thailand. Diarrhea is defined as patients showing

related symptoms of fecal incontinence diagnosed by a physician and participants signed the consent forms after brief explanation of research project. Samples were incubated in buffered peptone water (Oxoid, Hampshire, UK) at $37 \mathrm{C}^{\circ}$ overnight, plated on SS and XLD agar (Oxoid), and suspected Salmonella colonies indicated by using a triple sugar iron (TSI) slant (Oxoid, Hampshire, UK) assay and lysine iron agar (LIA) (Biomedia, Nontanuri, Thailand). Conventional biochemical tests (glucose fermentation, lactose oxidation, gas and $\mathrm{H} 2 \mathrm{~S}$ production, urease assay, methyl red staining, and indole, motility and Voges-Proskauer tests) were performed according to ISO 6579:2002.

117 The study protocols were approved by the Ethical Committee of Phayao University (no. 570204 118 0020). 
119

120

121

122

123

124

125

126

127

128

129

130

131

132

133

134

135

136

137

138

139

140

141

142

143

144

145

146

147

148

149

150

151

152

153

154

155

156

157

158

2. Determination of $\beta$-lactam antibiotic resistance profile and ESBL phenotype

Susceptibility to $\beta$-lactam antibiotics was performed using a disk diffusion method according to Clinical and Laboratory Standards Institute (CLSI) guidelines (CLSI, 2016) using ampicillin (AMP, $10 \mu \mathrm{g}$ ), cefotaxime (CTX, $30 \mu \mathrm{g}$ ), ceftazidime (CAZ,30 $\mu \mathrm{g}$ ), ciprofloxacin (CIP, $5 \mu \mathrm{g}$ ), ertapenem (ETP, $10 \mu \mathrm{g}$ ), and gentamycin (GEN, $10 \mu \mathrm{g}$ ) discs (Oxoid), with Escherichia coli ATCC 25922 as control. ESBL phenotype was evaluation using a double-dish method (CLSI. M100S, 2016) employing CTX alone and in combination with clavulanic acid (10 $\mu \mathrm{g})$ (Oxoid), with in-house known ESBL-producing and -negative E. coli strains as controls. A rapid ESBL was slightly modified from the ESBL NDP (Nordmann, Dortet \& Poirel, 2012), which is based on observation of color change due to acid production of ESBL-producing bacteria. Salmonella isolate was inoculated in one $\mathrm{ml}$ of NB broth (Oxoid, Hampshire, UK) and incubated at $37{ }^{\circ} \mathrm{C}$ overnight, each experiment conducted in duplicate. Then culture was centrifuged at $13,000 \mathrm{~g}$ for $2 \mathrm{~min}$, pellet washed twice with $700 \mu \mathrm{L}$ of $1 \mathrm{X} 10 \mathrm{mM}$ Tris $\mathrm{HCl} \mathrm{pH} 8.0$ containing $1 \mathrm{mM}$ EDTA (TE) buffer and mixed with $100 \mu \mathrm{L}$ of lysis buffer (B-PERII Bacterial Protein Extraction Reagent (Pierce/Thermo Scientific, Villebon-sur-Yvette, France), followed by $100 \mu \mathrm{L}$ of revelation solution $(0.05 \%(\mathrm{w} / \mathrm{v})$ phenol red) with and without $6 \mathrm{~g} / \mathrm{ml}$ cefotaxime and incubation at $37^{\circ} \mathrm{C}$ for $10 \mathrm{~min}$; yellow color in latter indicating positive result.

\section{Determination of Salmonella serotypes by HRM-PCR}

DNA was extracted from Salmonella isolates as previously described (McNerney et al., 2017). In brief, one $\mathrm{ml}$ aliquot of an overnight culture was sedimented as described above, washed twice with $400 \mu \mathrm{L}$ of TE buffer, resuspended in the same volume of TE buffer, incubated at $80^{\circ} \mathrm{C}$ for $20 \mathrm{~min}$, and cooled to ambient temperature. Then, a $50 \mu \mathrm{L}$ aliquot of lysozyme solution $(10 \mathrm{mg} / \mathrm{mL})$ was added and the solution incubated at $37^{\circ} \mathrm{C}$ for one hour with occasionally shaking, followed by addition of $75 \mu \mathrm{L}$ of $10 \% \mathrm{SDS} /$ proteinase $\mathrm{K}(10 \mathrm{mg} / \mathrm{mL})$ solution, vigorous vertexing and incubation at $65^{\circ} \mathrm{C}$ for $10 \mathrm{~min}$. Following addition of $100 \mu \mathrm{L}$ of $5 \mathrm{M} \mathrm{NaCl}$ and $100 \mu \mathrm{L}$ of prewarmed $\left(65^{\circ} \mathrm{C}\right) 10 \% \mathrm{~N}$-cetyl-N,N,N,-trimethyl ammonium bromide (CTAB)/ $5 \mathrm{M}$ $\mathrm{NaCl}$ solution, the mixture was further incubated at $65^{\circ} \mathrm{C}$ for $10 \mathrm{~min}$, followed by addition of $750 \mu \mathrm{L}$ of chloroform; isoamyl alcohol $(24: 1)$ and centrifugation at $11,000 \mathrm{~g}$ at $4^{\circ} \mathrm{C}$ for $5 \mathrm{~min}$. DNA in the upper aqueous was precipitated with ethanol, resuspended in $50 \mu \mathrm{L}$ of doubledistilled water and stored at $-20^{\circ} \mathrm{C}$ until used.

Multiplex HRM-PCR was performed using a combination of primers to amplify $f l j \mathrm{~B}$ (170 bp), gyrB (171 bp) and ycfQ (241 bp) (Table 1). HRM-PCR mixture $(10 \mu \mathrm{L})$ contained $1 \mu \mathrm{L}$ of DNA, $0.1 \mathrm{pmol}$ of gyrB, $0.075 \mathrm{pmol}$ of fljB and $0.075 \mathrm{pmol}$ of ycfQ primer pairs and $2 \mu \mathrm{L}$ of HOT FIREPol EvaGreen: no ROX Mix (Solis Biodye, Tartu, Estonia). Thermocycling was performed in a BIO-RAD CFX96TM Real-Time System (Bio-Rad, Hercules, CA, USA) as follows: $95^{\circ} \mathrm{C}$ for $15 \mathrm{~min}$, followed by 45 cycles of $95^{\circ} \mathrm{C}$ for $10 \mathrm{~s}, 60^{\circ} \mathrm{C}$ for $10 \mathrm{~s}$ and $72^{\circ} \mathrm{C}$ for $20 \mathrm{~s}$. Samples were then heated at $95^{\circ} \mathrm{C}$ for $1 \mathrm{~min}$, cooled to $40^{\circ} \mathrm{C}$ for $1 \mathrm{~min}$ and then heated from 70 to $95^{\circ} \mathrm{C}$ at 0.2 /s, with 25 fluorescence data acquisitions $/{ }^{\circ} \mathrm{C}$. HRM profiles were generated using a Precision

Peer] reviewing PDF | (2019:10:41955:1:1:NEW 4 Mar 2020) 
159

160

161

162

163

164

165

166

167

168

169

170

171

172

173

174

175

176

177

178

179

180

181

182

183

184

185

186

187

188

189

190

191

192

193

194

195

196

197

198

Melt Analysis software V 1.2 (BIO-RAD, Hercules, CA, USA) with sensitivity setting at 0.30, temperature shift at threshold 5, pre-melt normalization range from 80.87 to $81.51^{\circ} \mathrm{C}$, and postmelt normalization range from 89.17 to $89.92^{\circ} \mathrm{C}$. Following normalizing and temperature shifting, difference plots were generated relative to HRM profile of $S$. Bareilly (as baseline).

4. Hierarchical clustering of HRM curves using dynamic time warping (DTW) algorithm A dendrogram of normalized HRM curves was constructed using a DTW algorithm to determine distance measurements (Lu et al., 2017); the entire dendrogram construction was performed in Python programming language $(\mathrm{GV}, 1995)$. In short, a smooth spline approximation was determined from each normalized HRM curve using cubic splines of splrep function in scipy module (Jones E, Oliphant E, Peterson P, 2001) followed by a rate curve calculated from negative first derivative of the resulting spline employing a splev function. The curve was then znormalized using a zscore function to calculate DTW distances, in which $1^{\wedge} 2$-norm is the distance function (only between 80 and $94^{\circ} \mathrm{C}$ ). Hierarchical clustering based on DTW distances was preformed based on a neighbor-joining method to generate a dendrogram.

5. DNA profiling by ERIC PCR

ERIC-PCR mixture contained $0.1 \mu \mathrm{L}$ of extracted Salmonella DNA, primer set (Table 1), $2 \mu \mathrm{L}$ of HOT FIREPol Blend Master Mix Plus $10 \mathrm{mM} \mathrm{MgCl2} \mathrm{(Solis} \mathrm{Biodye),} \mathrm{and} \mathrm{double-distilled} \mathrm{water}$ to make $10 \mu \mathrm{L}$. Thermocycling was performed in Veriti Thermal Cycler, Applied Biosystems (Thermo Fisher Scientific, Waltham, MA, USA) as follows: $95^{\circ} \mathrm{C}$ for $15 \mathrm{~min}$; followed by 40 cycles of $95^{\circ} \mathrm{C}$ for $1 \mathrm{~min}, 54^{\circ} \mathrm{C}$ for $2 \mathrm{~min}$ and $72^{\circ} \mathrm{C}$ for $4 \mathrm{~min}$; and a final step at $72^{\circ} \mathrm{C}$ for $10 \mathrm{~min}$. Amplicons were separated by $4 \%$ agarose gel-electrophoresis, stained with RedSafe dye (INiRON, Kirkland, WA, USA) and recorded with a Molecular Imager Gel DOC ${ }^{\text {TM }}$ XR+ (BioRad, Berkeley, CA, USA) equipped with an Image Lab $^{\mathrm{TM}}$ software as JPEG images at 300 dpi resolution.

6. Analysis of ERIC PCR amplicon profile and phylogenetic tree Amplicon patterns generated by ERIC-PCR were analyzed and employing a curve-based algorithm (Pearson correlation) together with an open-source GelJ software (Heras et al., 2015) to create a similarity scale, and analysis of constructed phylogenetic tree clusters was by an unweighted pair-group using arithmetic averages algorithm (UPGMA) .

7. CRISPR 2 uniplex and HRM-PCR assays of Salmonella isolates

Salmonella isolates $(\mathrm{n}=55)$ included, in addition, previously characterized Salmonella spp. [S. 4,5,12:i- $(\mathrm{n}=15), S$. Typhimurium $(\mathrm{n}=6)$ and other Salmonella serotypes $(\mathrm{n}=8)]$ (Poonchareon et al., 2019a) (Poonchareon et al., 2019c). CRISPR 2 uniplex PCR mixture (10 $\mu \mathrm{L}$ ) contained $1 \mu \mathrm{L}$ of DNA, primer set (IDT, Singapore) (Table 1) and $2 \mu \mathrm{L}$ of HOT FIREPol Blend Master Mix Plus $10 \mathrm{mM} \mathrm{MgCl} 2$ (Solis Biodye). Thermocycling was carried out as described above but using the following conditions: $95^{\circ} \mathrm{C}$ for $12 \mathrm{~min} ; 35$ cycles of $94^{\circ} \mathrm{C}$ for $60 \mathrm{~s}$, $59^{\circ} \mathrm{C}$ for $60 \mathrm{~s}$ and $72^{\circ} \mathrm{C}$ for $90 \mathrm{~s}$; and a final step at $72^{\circ} \mathrm{C}$ for $7 \mathrm{~min}$. Amplicons were analyzed 
199

200

201

202

203

204

205

206

207

208

209

210

211

212

213

214

215

216

217

218

219

220

221

222

223

224

225

226

227

228

229

230

231

232

233

234

235

236

237 and recorded as described above. Amplicons of $S .4,[5], 12, \mathrm{i}$ - isolates from this study and those previously characterized (nos. 1, 23, 25, 35, 56, 76, 142, 152, 157, and 249) (Poonchareon et al., 2019a) (Poonchareon et al., 2019c) were purified from PCR clean up \& gel extraction kit;

GeneDirex ( Bio-Helix, Keelung City, Taiwan) and sequenced by First BASE Lab (Seri kembangan, Selangor, Malaysia). DNA sequences were aligned and compared with a BioEdit software package (https://bioedit.software.informer.com).

CRISPR 2 HRM-PCR mixture $(10 \mu \mathrm{L})$ contained $1 \mu \mathrm{L}$ of DNA, 0.1 pmol of CRISPR 2 F and 0.075 pmol of CRISPR 2_R (IDT) (Table 1), and $2 \mu$ L of HOT FIREPol EvaGreen: no ROX Mix (Solis Biodye) and thermocycling was performed as described above but under the following conditions: $95^{\circ} \mathrm{C}$ for $12 \mathrm{~min}$, followed by 35 cycles of $95^{\circ} \mathrm{C}$ for $60 \mathrm{~s}, 59^{\circ} \mathrm{C}$ for $60 \mathrm{~s}$ and $72^{\circ} \mathrm{C}$ for $90 \mathrm{~s}$. Samples were then heated at $95^{\circ} \mathrm{C}$ for $1 \mathrm{~min}$, cooled to $40^{\circ} \mathrm{C}$ for $1 \mathrm{~min}$ and $\mathrm{HRM}$ profiles generated and analyzed as described above but using HRM profile of $S$. Agona as baseline. Clustering of $S$. 4,5,12:i- isolates was achieved with a pre-melt normalization range of $87.7-88.2^{\circ} \mathrm{C}$ and a post-melt normalization range of $93.5-93.7^{\circ} \mathrm{C}$, with $S .4,5,12: 1-\mathrm{M} 76$ as reference isolate.

\section{Characterization of CRISPR 2 amplicon sequences}

CRISPR 2 DNA sequences in fasta format were uploaded to https://crisprcas.i2bc.parissaclay.fr/CrisprCasFinder/Index with default setting. Information of CRISPR 2 region (molecular signature of CRISPR 2 locus), e.g. DR consensus sequence, DR length and number of spacers, were provided directly in the form of DNA sequences or numeral data.

\section{Identification of bla alleles}

Reaction mixture $(10 \mu \mathrm{L})$ for multiplex PCR of bla alleles of interest contained $1 \mu \mathrm{L}$ of DNA, bla primer sets (IDT) (Table 1) and $2 \mu \mathrm{L}$ of HOT FIREPol Blend Master Mix Plus $10 \mathrm{mM}$ $\mathrm{MgCl} 2$ (Solis Biodye) and thermocycling was conducted as described above but using the following conditions: $95^{\circ} \mathrm{C}$ for $15 \mathrm{~min} ; 40$ cycles of $95^{\circ} \mathrm{C}$ for $40 \mathrm{~s}, 60^{\circ} \mathrm{C}$ for $40 \mathrm{~s}$ and $72^{\circ} \mathrm{C}$ for 60 $\mathrm{s}$; and a final step at $72^{\circ} \mathrm{C}$ for 7 minutes. Amplicons were analyzed (using $1.5 \%$ agarose gel) and recorded as described above. 


\section{Results}

239 1. Salmonella serotypes of clinical isolates from stools of diarrheal patients, Phayao Ram

240 Hospital, Phayao province.

241 Multiplex HRM-PCR of Salmonella flj $\mathrm{B}, g y r \mathrm{~B}$ and $y c f \mathrm{Q}$ amplicons from 26 patients stool

242 samples isolates generated 11 distinct HRM profiles (HRM_1-11) with HRM_1 predominant (n

$243=10$, indicative of $S .4,[5], 12, \mathrm{i}-)$, followed by HRM $6(\mathrm{n}=4$, indicative of $S$. Enteritidis $)$ and

244 HRM_8 $(\mathrm{n}=3$, indicative of $S$. Stanley) (Fig. 1). HRM_5 profile $(\mathrm{n}=2)$ was similar to those

245 previously identified for Salmonella serotypes $S$. Agona, $S$. Corvallis, $S$. Derby, and $S$. Kedougou

246 (Poonchareon et al., 2019b). The other seven HRM profiles were not characterized and

247 considered as indicative of rare or unknown Salmonella serotypes.

248 ERIC PCR was applied to characterize genetic relatedness of S. Enteritidis (HRM_6),

249 HRM_2, 3, 4 4, 5, 7, 9, 10, and 11 Salmonella isolates. Phylogenetic tree constructed from

250 ERIC PCR amplicon sizes revealed these Salmonella isolates clustered into three distinct clades

251 (Fig. 2). Salmonella isolates 378 and 454 (HRM_5) were in clade 1 and assigned S. Weltevreden.

252

253

254

255

256

257

258

259

260

261

262

263

264

265

266

267

268

269

270

271

272

273

274

275

276

277

All S. Enteritidis isolates (HRM_6) were grouped in clade 2, and Salmonella isolates with serotypes unidentified from multiplex HRM-PCR profiles were grouped together in clade 3 and still remained untyped except for Salmonella isolate 412 (HRM_4) that was assigned S. 4,5,12:i-.

2. Phylogenic tree based on multiplex HRM-PCR of clinical Salmonella isolates and association with other characteristics.

A DTW algorithm was applied to transform HRM-PCR profiles into numerical data to allow construction of a phylogenetic tree ( $\mathrm{Lu}$ et al., 2017), resulting in grouping of the 26 clinical isolates into six clades (Fig. 3). S. 4,5,12:i-, S. Enteritidis and S. Stanley was clustered in clade 2, 4 and 6, respectively while HRM types of unidentified serotypes were mainly distributed in clade 3 and 5 except HRM_5 (S. Weltevreden) and isolate 412 (HRM_4, S. 4,5,12:i-) was in clade 1 and 3 respectively. It is worth noting that $S .4,5,12: \mathrm{i}$ - isolates were clustered in clades $2(\mathrm{n}=8)$ and $3(\mathrm{n}=1)$, but three were unassigned. Ampicillin resistance was predominantly associated with blaTEM, and two ESBL-producing Salmonella isolates (based on a double-dish assay) harbored blaCTX group 1. One ESBL-producing S. 4,5,12:i-, isolate 412 (assigned by ERICPCR, Fig. 2) demonstrated a multidrug-resistant phenotype, including CIP resistance.

\section{CRISPR 2 uniplex and HRM-PCR analyses}

In order to simplify Salmonella serotyping based on multiplex PCR of $f l j \mathrm{~B}, g y r \mathrm{~B}$ and $y c f \mathrm{Q}$, uniplex PCR of CRISPR 2 locus was developed. The 26 clinical Salmonella isolates each generated a single amplicon, size of which was indicative of serotype when compared with known Salmonella serotypes, namely, 830 bp of $S$. Enteritidis and 1,700 bp of S. 4,5,12:i- (Fig 4). Salmonella isolate 412, shown by ERIC-PCR to be $S .4,5,12:$ i-, generated an amplicon of 1,700 bp. However, samples 378 and 454 (S. Weltevreden) and 312, 413 and 495 (S. Stanley) failed to demonstrated amplicons of consistent sizes. Amplicon sizes of the remaining samples did not correspond to the three Salmonella serotype standards. Thus, CRISPR2 uniplex PCR, 
278 although simpler to perform, had limited ability in providing definitive identification of

279 Salmonella serotypes based on amplicon sizes.

280 IHRM temperature-shifted difference profiles (relative to $S .4,5,12:$ i- M26) of CRISPR 2 281 uniplex amplicons of the $11 \mathrm{~S} .4,5,12$ :i- isolates from this study and other previously identified 282 samples produced three different profiles (clusters 1-3) (Fig 5). Cluster 1 contained five known 283 human and four from minced pork samples, cluster 2 four isolates from this study and three 284 known human isolates and cluster 3 seven isolates from this study (including samples 345 and 285394 that were not grouped in any of the six clades inferred from multiplex HRM PCR profiling 286 (Fig. 3) and sample 412) and one known human sample (Table 2). The three ESBL-producing 287 Salmonella clinical isolates in cluster 1 carried a novel variant DR consensus sequence (Fabre et 288 al., 2012). Interestingly, ESBL-producing Salmonella isolate 412 (cluster 3), isolated in 2017, 289 was not grouped with the other three ESBL-producing $S .4,5,12:$ i- isolates collected earlier, 290 suggesting the possibility of a different evolution trajectory of isolate 412.

291 5. Seasonal prevalence of Salmonella serotypes collected from stools of patients, Phayao Ram 292 Hospital

293 Over a period of one calendar year, infection at Phayao Ram Hospital of Salmonella 294 serotypes identified using multiplex HRM-PCR profiling peaked during the summer period 295 (April to August) (Fig. 6), with, as expected, S. 4,5,12:i- being predominant, but all serotypes 296 were represented. Although minor peaks were discernable, they are not of significance owing to 297 the limited number of Salmonella isolates examined.

\section{Discussion}

\section{Discussion}

300

301

302

303

304

305

306

307

308

309

310

311

312

313

314

315

316

317

In Thailand, Salmonella is the leading cause of food poisoning with approximately 359$389 / 100000$ of the population affected (National Disease Surveiilance, 2560). In Phayao province, the estimated number of cases of food poisoning increased from 143 to 288/100,000 between 2015 to 2016, but with no reported mortality (National Antimicrobial Resistance Surveillance Center, 2017). Salmonella spp. isolated from stool of patients, especially from infants, are consistent among studies irrespective of geographical locations (Pulsrikarn et al., 2013), (Parry \& Threlfall, 2008). There were 105 cases admitted to Phayao Hospital from Salmonella food poisoning from January to December 2014 (Phayao Hospital, 2015).

Multiplex HRM-PCR assay of Salmonella serotypes, although not able to type all eight serotypes responsible for food poisoning, is adequate in identifying the majority of pertinent clinical Salmonella serotypes in particular $S .4,5,12: \mathrm{i}-$ and $S$. Enteritidis that are frequently identified as the serotypes responsible for human and veterinary infections worldwide (Frasson et al., 2016). The method is less time consuming, with a turn-around time of approximately 8-12 hours, compared to 3-5 days using standard conventional technique and is less complicated to perform. A number of different primers have been employed in multiplex PCR for genotyping and serotyping Salmonella spp. (O'Regan et al., 2008), (Kim et al., 2009), but the numbers have been kept to a minimum owing to the vast variety of HRM profiles that could be generated (Masek et al., 2014).

Peer) reviewing PDF | (2019:10:41955:1:1:NEW 4 Mar 2020) 
318 S. 4,5,12:i:- is considered a major virulent Salmonella serotype that has successfully dispersed 319 throughout many geographical areas and harbor various groups of antibiotic resistance genes 320 (Guerra et al., 2000). In the present study, most of the Salmonella spp. collected from diarrheal 321 patients were resistant to only ampicillin, although the identification of an ESBL- producing $S$.

322

323

324

325

326

327

328

329

330

331

332

333

334

335

336

337

338

339

340

341

342

343

344

345

346

347

348

349

350

351

352

353

354

355

356 4,5,12:i- suggests a possible contamination of the chain of food production originating from swine and chicken farms in this region (Angkititrakul et al., 2005). ESBL-producing and MDR S.4,5,12:i:- harboring virulent blaCTX group 1 is frequently found in other regions of Thailand (Amavisit, Boonyawiwat \& Bangtrakulnont, 2005) and in Southeast Asian countries (Tamang et al., 2011) and other continents (Yang et al., 2015). Several rapid ESBL tests are available with demonstrated superiority in reducing operational time, simplicity in procedure and high accuracy (Nordmann, Dortet \& Poirel, 2012). A convenient and rapid ESBL test based on observed color change of direct samples (Dierikx et al., 2010) was employed in our study without any discrepancies previously reported (Srisrattakarn et al., 2016). Because the commonly prescribed drugs for gastroenteritis treatment are the quinolone and $\beta$-lactam-related antibiotics, emergence of MDR Salmonella resistant to both ciprofloxacin and cefotaxime has compromised use of the drugs in cases with complications, such as bacteremia with underlying diseases or in children (Guarino, Bruzzese \& Giannattasio, 2018). Association of resistance to a particular $\beta$-lactam antibiotic with a Salmonella serotype highlights the usefulness of rapid serotyping and the emergence of $S .4,5,12: i-$ resistant in both ciprofloxacin and cefotaxime indicates the need for implementation of surveillance in local hospitals. Although the peak season for Salmonella infection in the study region was in the summer season, consistent predominance of virulent $S$. 4,5,12:i- among the isolates throughout the year is be of concern.

CRISPR polymorphism has been effectively applied in typing and subtyping several clinically important bacteria such as Mycobacterium tuberculosis and Salmonella spp. (Kamerbeek et al., 1997), (Liu et al., 2011). A significantly improved CRISPR-based method (CRISPOL) for Salmonella subtyping was effectively applied to characterize more than 2,000 isolates of Salmonella Typhimurium and variant S. I 4,5,12:i- (Fabre et al., 2012). However, a simple and rapid conventional PCR assay was also developed to characterize certain specific serotypes (Xiong et al., 2016). Our small cohort study indicates a preliminary protocol of CRISPR 2 uniplex PCR allowed simultaneous detection and differentiation among three clinically important Salmonella serotypes, namely $S .4,[5], 12: i:, S$. Enteritidis and $S$.

Typhimurium but this needs confirmation using a larger collection of Salmonella isolates. This CRISPR 2 uniplex PCR method should be less complicated to adapt in quantitative analysis of Salmonella contamination in food products compared to quantitative multiplex PCR (Maurischat et al., 2015). In addition, application of CRISPR HRM-PCR profiling to address CRISPR 1 and 2 sequence polymorphisms has allowed differentiation of eleven Salmonella serotypes (Bratčikov \& Mauricas, 2009). CRISPR 2 HRM-PCR profiling in our hands indicated $S$. 4,5,12:i- isolates could be readily differentiated, possibly reflecting differences in evolutionary trajectories of the $S .4,[5], 12: i$ - isolates from this region of the country. 
357

358

359

360

361

362

363

364

365

366

367

368

369

370

371

372

373

374

375

376

377

378

379

380

381

382

383

384

385

386

387

388

389

390

391

392

393

394

The limited number of $S .4,5,12: \mathrm{i}$ - isolates available in this particular area necessitates further studies of a larger cohort of $S .4,[5], 12: i$ i isolates not only from the study area but from various epidemiology backgrounds to enable correlation of important virulent features with epidemiological settings. Interestingly, application of CRISPR 1 and 2 PCR methods for Salmonella identification allowed detection of multiple Salmonella serovars in a single sample (Thompson et al., 2018). This application of CRISPR 2 PCR for identification of multiple Salmonella serotypes in a specimen will be further explored.

\section{Conclusions}

The study demonstrates the ability of applying multiplex HRM-PCR profiling and a novel protocol of CRISPR 2 uniplex PCR together with HRM profiling to rapidly and conveniently serotype clinically important Salmonella isolates. In conjunction with a rapid ESBL test, antibiogram profile and detection of $\beta$-lactamase genes should provide a powerful strategy for predicting antibiotic resistance phenotypes associated with particular serotypes. Moreover, CRISPR 2 HRM-PCR profiling provides a novel tool for classification of S. 4,[5],12:iaccording to evolutionary trajectories stemming from various epidemiological settings.

\section{Acknowledgements}

The author received no funding for this work. The authors appreciated research cooperation from Veterinary Research and Development Center (Upper Northern Region). Finally, we were indebted Prof. Emeritus Prapon Wilairat, Mahidol University for providing invaluable suggestions and encouragement and for proof-reading the final manuscript.

\section{References}

Amavisit P, Boonyawiwat W, Bangtrakulnont a. 2005. Characterization of Salmonella enterica Serovar Typhimurium and Monophasic Salmonella Serovar $1,4,[5], 12$ : i : - Isolates in Thailand. 43:2736-2740. DOI: 10.1128/JCM.43.6.2736.

Angkititrakul S, Chomvarin C, Chaita T, Kanistanon K, Waethewutajarn S. 2005. Epidemiology of antimicrobial resistance in Salmonella isolated from pork, chicken meat and humans in Thailand. Southeast Asian Journal of Tropical Medicine and Public Health 36:1510-1515.

Bangtrakulnonth A, Pornreongwong S, Pulsrikarn C, Sawanpanyalert P, Hendriksen RS, Lo Fo Wong DM a, Aarestrup FM. 2004. Salmonella Serovars from Humans and Other Sources in 
395 Thailand, 1993-2002. Emerging Infectious Diseases 10:131-136. DOI: 10.3201/eid1001.023960781.

397

398

399

400

401

402

403

404

405

406

407

408

409

410

411

412

413

414

415

416

417

418

419

420

421

422

423

424

425

426

427

428

429

430

431

432

433

Boonmar S, Bangtrakulnonth A, Pornruangwong S, Samosornsuk S, Kaneko KI, Ogawa M. 1998. Significant increase in antibiotic resistance of Salmonella isolates from human beings and chicken meat in Thailand. Veterinary Microbiology 62:73-80.

Bratčikov M, Mauricas M. 2009. The use of high-resolution melting analysis for Salmonella spp. CRISPR sequence genotyping. Acta medica Lituanica 16:98-102. DOI: 10.2478/v10140-0090014-8.

Cantón R, González-Alba JM, Galán JC. 2012. CTX-M enzymes: Origin and diffusion. Frontiers in Microbiology 3:1-19. DOI: 10.3389/fmicb.2012.00110.

CLSI. 2016. M100S: Performance Standards for Antimicrobial Susceptibility Testing. Wayne, PA, USA: Clinical and Laboratory Standards Institute.

Dierikx C, van Essen-Zandbergen A, Veldman K, Smith H, Mevius D. 2010. Increased detection of extended spectrum beta-lactamase producing Salmonella enterica and Escherichia coli isolates from poultry. Veterinary Microbiology 145:273-278. DOI: 10.1016/j.vetmic.2010.03.019.

Fabre L, Zhang J, Guigon G, Le Hello S, Guibert V, Accou-Demartin M, de Romans S, Lim C, Roux C, Passet V, Diancourt L, Guibourdenche M, Issenhuth-Jeanjean S, Achtman M, Brisse S, Sola C, Weill FX. 2012. Crispr typing and subtyping for improved Laboratory surveillance of Salmonella infections. PLoS ONE 7. DOI: 10.1371/journal.pone.0036995.

Fei X, He X, Guo R, Yin C, Geng H, Wu K, Yin K, Geng S, Pan Z, Li Q, Jiao X. 2017. Analysis of prevalence and CRISPR typing reveals persistent antimicrobial-resistant Salmonella infection across chicken breeder farm production stages. Food Control 77:102-109. DOI: 10.1016/j.foodcont.2017.01.023.

Frasson I, Bettanello S, Canale E De, Richter SN, Palù G. 2016. Serotype epidemiology and multidrug resistance patterns of Salmonella enterica infecting humans in Italy. Gut Pathogens:17. DOI: 10.1186/s13099-016-0110-8.

Galanis E, Lo Fo Wong DMA, Patrick ME, Binsztein N, Cieslik A, Chalermchaikit T, AidaraKane A, Ellis A, Angulo FJ, Wegener HC. 2006. Web-based surveillance and global Salmonella distribution, 2000-2002. Emerging Infectious Diseases 12:381-388.

Peer) reviewing PDF | (2019:10:41955:1:1:NEW 4 Mar 2020) 
434 Guarino A, Bruzzese E, Giannattasio A. 2018. Antibiotic treatment of acute gastroenteritis in 435 children. F1000Research 7:1-10. DOI: 10.12688/f1000research.12328.1.

436

437 Guerra B, Laconcha I, Soto SM, Gonzalez-Hevia Mangeles, Mendoza MC. 2000. Molecular 438 characterisation of emergent multiresistant Salmonella enterica serotype [4,5,12:1:-] organisms 439 causing human salmonellosis. FEMS Microbiology Letters 190:341-347.

440

441 GV R. 1995. Python tutorial, Technical Report CS-R9526, Centrum voor Wiskunde en 442 Informatica (CWI). Amsterdam.

443

Heras J, Domínguez C, Mata E, Pascual V, Lozano C, Torres C, Zarazaga M. 2015. GelJ - a tool 445 for analyzing DNA fingerprint gel images. BMC Bioinformatics 16:1-8. DOI: 10.1186/s12859446 015-0703-0.

447

448

449

Horvath P, Barrangou R. 2010. CRISPR/Cas, the immune system of Bacteria and Archaea. Science 327:167-170. DOI: 10.1126/science.1179555.

450

451

ISO 6579:2000. 2002. Microbiology of food and animal feeding stuffs - Horizontal method for

452

453

454 the detection of Salmonella spp. Geneva, Switzerland.

455

Jansen R, Van Embden JDA, Gaastra W, Schouls LM. 2002. Identification of genes that are associated with DNA repeats in prokaryotes. Molecular Microbiology 43:1565-1575. DOI:

456 10.1046/j.1365-2958.2002.02839.x.

457

Jones E, Oliphant E, Peterson P. 2001. Open Source Scientific Tools for Python. SciPy. Kamerbeek J, Schouls L, Kolk A, Van Agterveld M, Van Soolingen D, Kuijper S, Bunschoten A, Molhuizen H, Shaw R, Goyal M, Van Embden J. 1997. Simultaneous detection and strain differentiation of Mycobacterium tuberculosis for diagnosis and epidemiology. Journal of Clinical Microbiology 35:907-914.

465

Kauffman F. 1972. Serologic diagnosis of Salmonella species. Munksgaard, Copenhagen,

466 Denmark, Copenhagen, Denmark.

468

Kim S, Frye JG, Hu J, Fedorka-Cray PJ, Gautom R, Boyle DS. 2006. Multiplex PCR-based method for identification of common clinical serotypes of Salmonella enterica subsp. enterica. Journal of Clinical Microbiology 44:3608-3615. DOI: 10.1128/JCM.00701-06.

470

471 Kim J, Jeon S, Rhie H, Lee B, Park M, Lee H, Lee J, Kim S. 2009. Rapid Detection of Extended

472 Spectrum $\beta$-Lactamase (ESBL) for Enterobacteriaceae by use of a Multiplex PCR-based Method. 473 Infect Chemother 41:181-184. DOI: 10.3947/ic.2009.41.3.181. 
474 Li Q, Wang X, Yin K, Hu Y, Xu H, Xie X, Xu L, Fei X, Chen X, Jiao X. 2018. Genetic analysis 475 and CRISPR typing of Salmonella enterica serovar Enteritidis from different sources revealed 476 potential transmission from poultry and pig to human. International Journal of Food 477 Microbiology 266:119-125. DOI: 10.1016/j.ijfoodmicro.2017.11.025.

478

479

Liu F, Kariyawasam S, Jayarao BM, Barrangou R, Gerner-Smidt P, Ribot EM, Knabel SJ,

481

482

483

484

485

486

487

488

489

490

491

492

493

494

495

496

497

498

499

500

501

502

503

504

505

506

507

508

509

510

511

512 Dudley EG. 2011. Subtyping Salmonella enterica serovar enteritidis isolates from different sources by using sequence typing based on virulence genes and clustered regularly interspaced short palindromic repeats (CRISPRs). Applied and Environmental Microbiology 77:4520-4526. DOI: 10.1128/AEM.00468-11.

Lu S, Mirchevska G, Phatak SS, Li D, Luka J, Calderone RA, Fonzi WA. 2017. Dynamic time warping assessment of highresolution melt curves provides a robust metric for fungal identification. PLoS ONE 12:1-21. DOI: 10.1371/journal.pone.0173320.

Masek BJ, Hardick J, Won H, Yang S, Hsieh YH, Rothman RE, Gaydos CA. 2014. Sensitive detection and serovar differentiation of typhoidal and nontyphoidal Salmonella enterica species using 16S rRNA gene PCR coupled with high-resolution melt analysis. Journal of Molecular Diagnostics 16:261-266. DOI: 10.1016/j.jmoldx.2013.10.011.

Maurischat S, Baumann B, Martin A, Malorny B. 2015. Rapid detection and specific differentiation of Salmonella enterica subsp. Enterica Enteritidis, Typhimurium and its monophasic variant 4,[5],12:i: By real-time multiplex PCR. International Journal of Food Microbiology 193:8-14. DOI: 10.1016/j.ijfoodmicro.2014.10.004.

McNerney R, Clark TG, Campino S, Rodrigues C, Dolinger D, Smith L, Cabibbe AM, Dheda K, Schito M. 2017. Removing the bottleneck in whole genome sequencing of Mycobacterium tuberculosis for rapid drug resistance analysis: a call to action. International Journal of Infectious Diseases 56:130-135. DOI: 10.1016/j.jijid.2016.11.422.

National Antimicrobial Resistance Surveillance Center. 2017. National Antimicrobial Resistance Surveillance Center, Thailand (NARST) Antibiograms.

National Disease Surveiilance. 2560.National Disease Surveiilance (Report 506). Available at http://www.boe.moph.go.th/ (accessed March 1, 2016).

Nordmann P, Dortet L, Poirel L. 2012. Rapid detection of extended-spectrum- $\beta$-lactamaseproducing Enterobacteriaceae. Journal of Clinical Microbiology 50:3016-3022. DOI: 10.1128/JCM.00859-12. 
513 O'Regan E, McCabe E, Burgess C, McGuinness S, Barry T, Duffy G, Whyte P, Fanning S,

514 Španová A. 2008. Development of a real-time multiplex PCR assay for the detection of multiple

515 Salmonella serotypes in chicken samples. BMC microbiology 8:1-11. DOI: 10.1186/1471-2180-

516 8-156.

517

518 Padungtod P, Kaneene JB. 2006. Salmonella in food animals and humans in northern Thailand.

519 International Journal of Food Microbiology 108:346-354. DOI:

520 https://doi.org/10.1016/j.ijfoodmicro.2005.11.020.

521

522 Parry CM, Threlfall EJ. 2008. Antimicrobial resistance in typhoidal and nontyphoidal

523 Salmonellae. Current Opinion in Infectious Diseases 21:531-538.

524

525

Phayao Hospital. 2015. Percentage of Susceptible Oranisms isolated by sites from Phayao

526 Hospital. Phayao.

527

528

529

Poonchareon K, Narong Nuanmuang, Prommuang P, Sriisan S. 2019a. High-resolution melting-

530 curve analysis for serotyping of Salmonella spp. group B isolated from minced pork in the

531 Northern part of Thailand. Journal of Associated Medical Sciences 52:62-71. DOI:

532

533

Poonchareon K, Pulsrikarn C, Khamvichai S, Tadee P. 2019b. Feasibility of high resolution

534 melting curve analysis for rapid serotyping of Salmonella from hospitalised patients. Journal of

535 Associated medical Sciences 52:36-40. DOI: 10.14456/jams.2018.3.

536

537 Poonchareon K, Pulsrikarn C, Nuanmuang N, Khamai P. 2019c. Effectiveness of BOX-PCR in

538 Differentiating Genetic Relatedness among Salmonella enterica Serotype 4,[5],12:i:- Isolates from Hospitalized Patients and Minced Pork Samples in Northern Thailand. International Journal

540 of Microbiology 2019. DOI: 10.1155/2019/5086240.

541

542 Pulsrikarn C, Pornreongwong S, Tribuddharat C, Meethai C, Srifuengfung S. 2013. Serogroup

543 and Serovar Distribution of Salmonella in Siriraj Hospital. Siriraj Med J 65:s34-s37.

544 Rupp ME, Fey PD. 2003. Extended Spectrum Beta-Lactamase (ESBL)-Producing

545 Enterobacteriaceae: Considerations for Diagnosis, Prevention and Drug Treatment. Drugs

$546 \quad 63: 353-365$.

547

548 Shariat N, Dudley EG. 2014. CRISPRs: Molecular Signatures Used for Pathogen Subtyping.

549 Applied and Environmental Microbiology 80:430-439. DOI: 10.1128/AEM.02790-13.

550

551 Sirsichote P, Bangtrakulnonth A, Tianmanee K, Unahalekhaka A, Oulai A, Chittaphithakchai P,

552 Kheowrod W, Hendriksen RS. 2010. Serotypes and antimicrobial resistance of Salmonella 
553 enterica Spp. in central Thailand, 2001-2006. Southeast Asian Journal of Tropical Medicine and 554 Public Health 41:1405-1415.

555

556

557

558

559

560

561

562

563

564

565

566

567

568

569

570

571

572

573

574

575

576

577

578

579

580

581

582

583

584

585

586

587

588

589

Srisrattakarn A, Lulitanond A, Wilailuckana C, Charoensri N, Wonglakorn L, Piyapatthanakul S, Supajeen A, Chanawong A. 2016. Modification and evaluation of the Carba NP test by use of paper strip for simple and rapid detection of carbapenemase-producing Enterobacteriaceae. World Journal of Microbiology and Biotechnology 32:1-8. DOI: 10.1007/s11274-016-2064-x.

Tamang MD, Nam HM, Kim TS, Jang GC, Jung SC, Lim SK. 2011. Emergence of extendedspectrum Beta-lactamase (CTX-M-15 and CTX-M-14)-producing nontyphoid Salmonella with reduced susceptibility to ciprofloxacin among food animals and humans in Korea. Journal of Clinical Microbiology 49:2671-2675.

Thompson CP, Doak AN, Amirani N, Schroeder EA, Wright J, Kariyawasam S, Lamendella R, Shariat NW. 2018. High-resolution identification of multiple Salmonella serovars in a single sample by using CRISPRSeroSeq. Applied and Environmental Microbiology 84:1-13. DOI: 10.1128/AEM.01859-18.

Uzzau S, Brown DJ, Wallis T, Rubino S, Leori G, Bernard S, Casadesús J, Platt DJ, Olsen JE. 2000. Host adapted serotypes of Salmonella enterica. Epidemiology and infection 125:229-255. Velge P, Cloeckart A, Barrow P. 2005. Emergence of Salmonella epidemics: The problems related to Salmonella enterica serotype Enteritidis and multiple antibiotic resistance in other major serotypes. Veterinary Research 36:267-288.

Xiong D, Song L, Geng S, Tao J, An S, Pan Z, Jiao X. 2016. One-step PCR detection of Salmonella Pullorum/Gallinarum using a novel target: The flagellar biosynthesis gene flhB. Frontiers in Microbiology 7:1-7. DOI: 10.3389/fmicb.2016.01863.

Yang X, Wu Q, Zhang J, Huang J, Guo W, Cai S. 2015. Prevalence and characterization of monophasic Salmonella serovar 1,4,[5],12:i:-of food origin in China. PLoS ONE 10:1-10. DOI: 10.1371/journal.pone.0137967.

Zeinzinger J, Pietzka AT, Stöger A, Kornschober C, Kunert R, Allerberger F, Mach R, Ruppitsch W. 2012. One-step triplex high-resolution melting analysis for rapid identification and simultaneous subtyping of frequently isolated Salmonella serovars. Applied and Environmental Microbiology 78:3352-3360. DOI: 10.1128/AEM.07668-11.

Peer) reviewing PDF | (2019:10:41955:1:1:NEW 4 Mar 2020) 
Table $\mathbf{1}$ (on next page)

Primers used in this study 


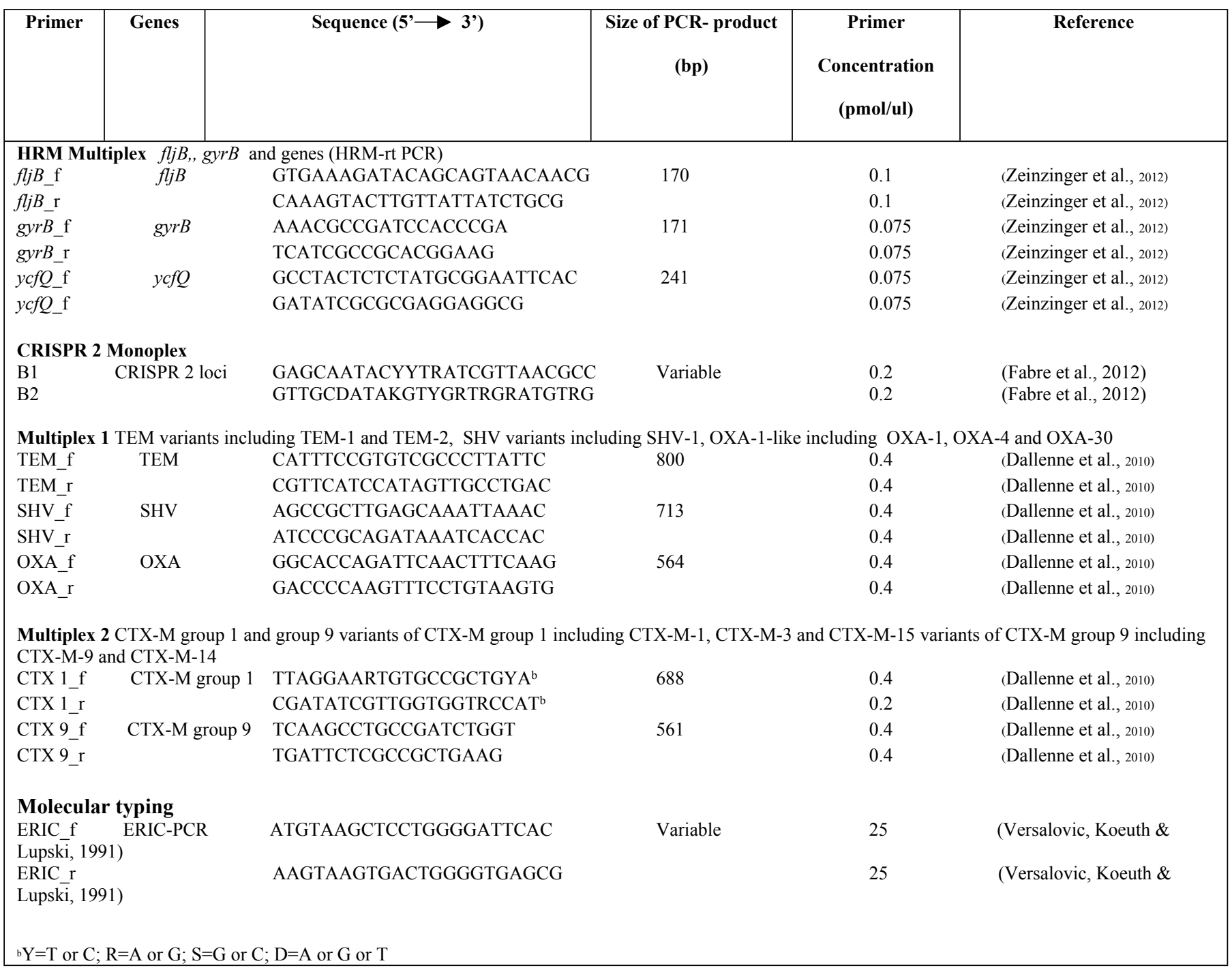

1 


\section{Table 2 (on next page)}

Properties of Salmonella 4,5,12:i- isolates present in clusters based on CRISPR 2 uniplex high resolution melting PCR profiles.

DR, direct repeat; ESBL, extended spectrum beta lactamase; ref, reference strain; Spacer count, number of spacers in CRISPR 2 locus; similar DNA sequence of DR concensus labelled with the same superscript number. 


\begin{tabular}{|c|c|c|c|c|c|c|c|c|c|c|c|}
\hline Cluster & Serotype & ID & Source & $\begin{array}{r}\text { Year of } \\
\text { isolation }\end{array}$ & ESBL & $\begin{array}{l}\text { Amplicon size } \\
\text { (bp) }\end{array}$ & $\begin{array}{c}\text { CRISPR } \\
\text { length (bp) }\end{array}$ & $\begin{array}{c}\text { Spacer } \\
\text { count }\end{array}$ & DR concensus sequence & $\begin{array}{l}\text { DR Length } \\
\text { (bp) }\end{array}$ & $\begin{array}{c}\text { Group (\% } \\
\text { Identity) }\end{array}$ \\
\hline \multirow{9}{*}{$\begin{array}{c}\text { Cluster } \\
1\end{array}$} & $4,5,12: \mathrm{i}-$ & M1 & Human & 2015 & \multirow{9}{*}{$\begin{array}{l}+ \\
+ \\
+\end{array}$} & 1,959 & 579 & 21 & CGGTTTATCCCCGCTGGCGCGGGGAACAC $^{1}$ & 29 & $\begin{array}{c}3,2(99.45) \\
1(50.69)\end{array}$ \\
\hline & $4,5,12: \mathrm{i}-$ & M25 & Human & 2015 & & 1,959 & 1,493 & 24 & CGGTTTATCCCCGCTGGCGCGGGGAACAC ${ }^{1}$ & 29 & $1(100)$ \\
\hline & $4,5,12$ : i- & M152 & Human & 2015 & & 1,959 & 1,493 & 24 & GTGTTCCCCGCGCCAGCGGGGATAAACCG $^{2}$ & 29 & $2(100)$ \\
\hline & $4,5,12$ : i- & M157 & Human & 2015 & & 1,959 & 1,493 & 24 & GTGTTCCCCGCGCCAGCGGGGATAAACCG $^{2}$ & 29 & $2(100)$ \\
\hline & $4,5,12$ : i- & M249 & Human & 2016 & & 1,959 & 1,493 & 24 & GTGTTCCCCGCGCCAGCGGGGATAAACCG ${ }^{2}$ & 29 & $2(100)$ \\
\hline & $4,5,12: \mathrm{i}-$ & En11 & Minced pork & 2017 & & & & & & & \\
\hline & $4,5,12$ : i- & En21 & Minced pork & 2017 & & & & & & & \\
\hline & $4,5,12$ : i- & En20 & Minced pork & 2017 & & & & & & & \\
\hline & $4,5,12$ : i- & En29 & Minced pork & 2017 & & & & & & & \\
\hline \multirow{7}{*}{$\begin{array}{c}\text { Cluster } \\
2\end{array}$} & $4,5,12$ : i- & M23 & Human & 2015 & & 1,959 & 1,493 & 21 & CGGTTTATCCCCGCTGGCGCGGGGAACAC ${ }^{1}$ & 29 & $1(100)$ \\
\hline & $4,5,12$ : i- & M56 & Human & 2015 & & 1,959 & 1,493 & 24 & CGGTTTATCCCCGCTGGCGCGGGGAACAC 1 & 29 & $1(100)$ \\
\hline & $4,5,12$ : i- & M142 & Human & 2015 & & 1,959 & 1,493 & 21 & CGGTTTATCCCCGCTGGCGCGGGGAACAC 1 & 29 & $1(100)$ \\
\hline & $4,5,12$ : i- & 444 & Human & 2017 & & & & & & & \\
\hline & $4,5,12$ : i- & 474 & Human & 2017 & & & & & & & \\
\hline & $4,5,12$ : i- & 484 & Human & 2017 & & & & & & & \\
\hline & $4,5,12: \mathrm{i}-$ & 497 & Human & 2017 & & & & & & & \\
\hline \multirow{9}{*}{$\begin{array}{c}\text { Cluster } \\
3\end{array}$} & $4,5,12$ : i- & M35 & Human & 2015 & & 1,959 & 1,493 & 24 & GTGTTCCCCGCGCCAGCGGGGATAAACCG & 29 & $2(100)$ \\
\hline & $4,5,12: \mathrm{i}-$ & 316 & Human & 2016 & & & & & & & \\
\hline & $4,5,12$ : i- & 345 & Human & 2016 & & & & & & & \\
\hline & $4,5,12: \mathrm{i}-$ & 350 & Human & 2016 & & & & & & & \\
\hline & $4,5,12$ : i- & 392 & Human & 2016 & & & & & & & \\
\hline & $4,5,12$ : i- & 394 & Human & 2016 & & & & & & & \\
\hline & $4,5,12: \mathrm{i}-$ & 412 & Human & 2017 & & & & & & & \\
\hline & $4,5,12$ : i- & 458 & Human & 2017 & & & & & & & \\
\hline & $4,5,12$ : i- & EN8 & Minced pork & 2017 & + & & & & & & \\
\hline ref & $4,5,12: \mathrm{i}-$ & M76 & Human & 2015 & + & 1959 & 1493 & 24 & CGGTTTATCCCCGCTGGCGCGGGGAACAC 1 & 29 & $1(100)$ \\
\hline
\end{tabular}




\section{Figure 1}

High resolution temperature-shifted difference melting profiles of multiplex PCR amplicons from clinical Salmonella isolates of diarrheal patients stools ( $n=26$ ), Phayao Ram Hospital, Phayao province, Thailand (2016-2017).

Multiplex PCR of $f l j B, y r B$ and $y c f Q$ was carried out employing primer pairs listed in Table 1. Temperature-shifted difference profiles relative to $S$. Bareilly were produced using a Precision Melt Analysis software V 1.2 (BIO-RAD, Hercules, CA, USA). (A) HRM profiles of Salmonella isolates (assigned HRM 1-11). (B) HRM profiles of the three most prevalent HRM profiles and their assigned Salmonella serotypes. (C) HRM_5 profile compared to known Salmonella serotypes (Poonchareon et al., 2019b). RFU, relative fluorescence unit. 

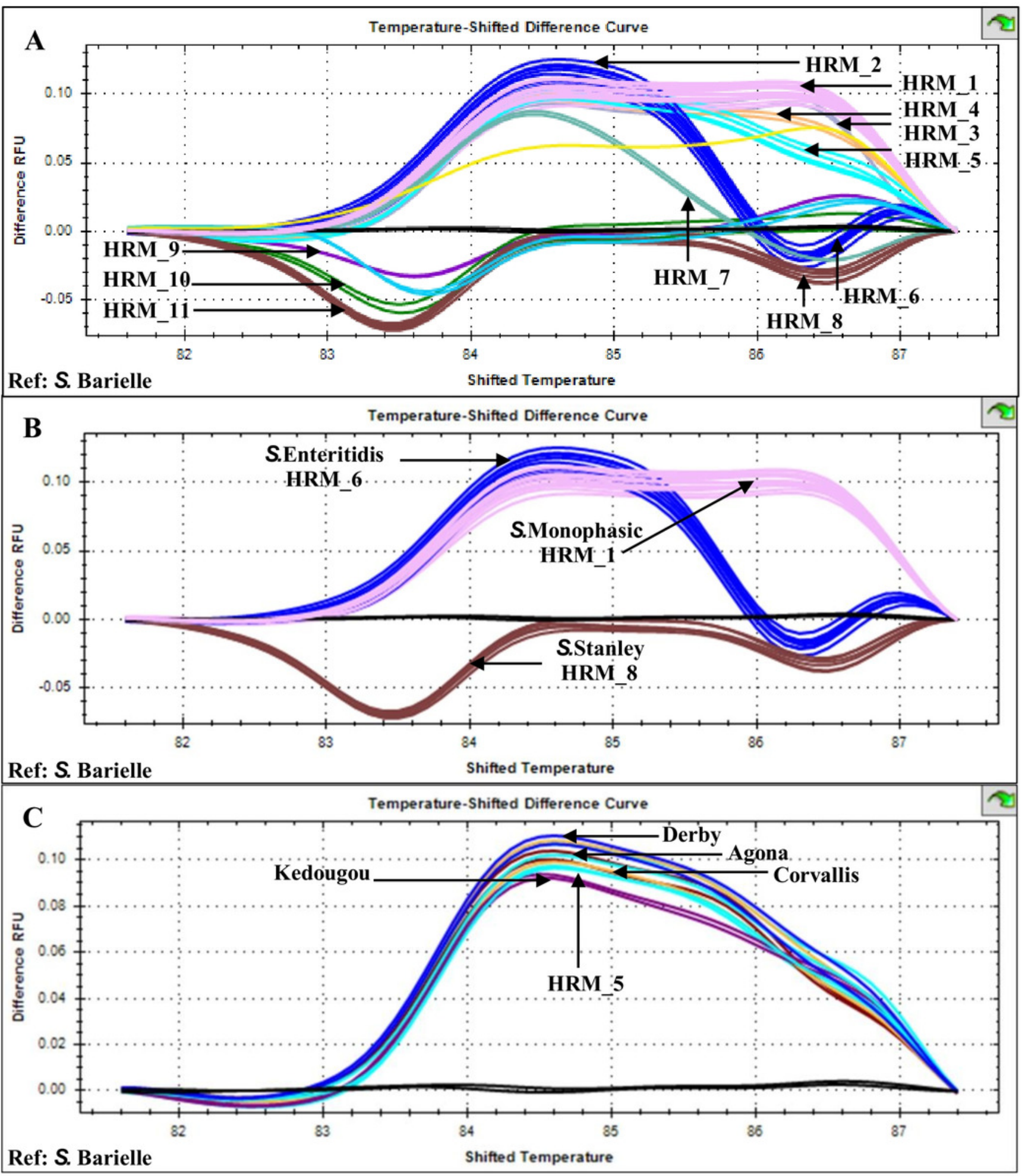


\section{Figure 2}

Phylogeny tree of repetitive element-based (ERIC)-PCR amplicon size profiles of Salmonella isolates from diarrheal patients stools, Phayao Ram Hospital, Phayao province, Thailand (2016-2017).

ERIC-PCR was performed using primers listeded in Table 1. The phylogeny tree was constructed using an unweighted pair-group using arithmetic averages algorithm. Clustering into clades employed a curve-based algorithm (Pearson correlation) together with an opensource GelJ software (Heras et al., 2015). *Known Salmonella serotypes. HRM, multiplex high resolution melting PCR; ND, no designation of serotype. 


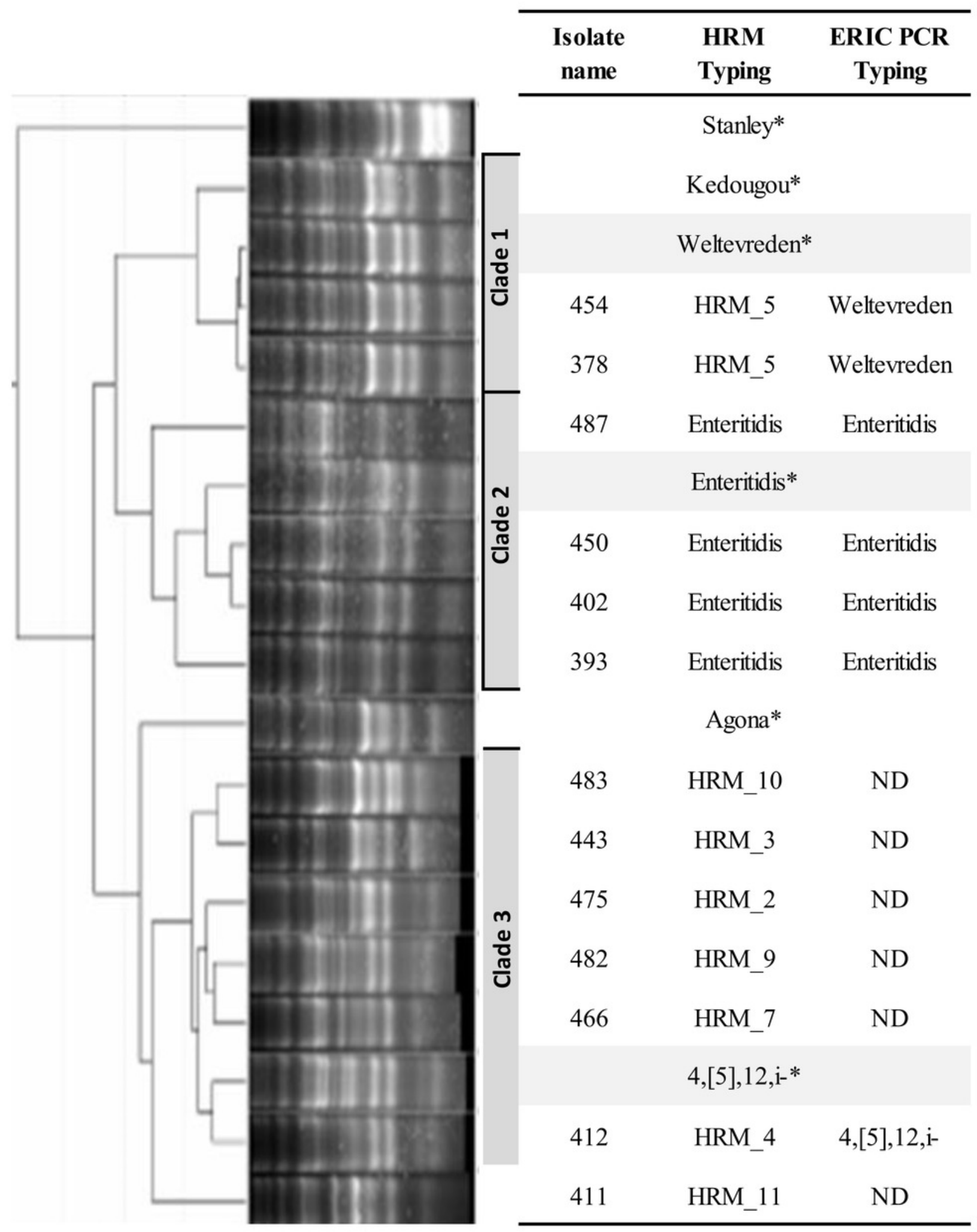




\section{Figure 3}

Phylogeny tree based on multiplex high resolution melting (HRM) PCR profiles of Salmonella isolates $(n=26$ ) from diarrheal patients stools, Phayao Ram Hospital, Phayao province, Thailand (2016-2017).

Phylogeny tree was constructed using a dynamic time warping algorithm (Python platform). Properties of the clinical Salmonella isolates are also shown. Salmonella isolate of known serotype is marked with an asterisk. ESBL, extended spectrum $\beta$-lactamase producer; ERIC PCR Typing, repetitive element-based PCR amplicon size profile; HRM Typing, multiplex HRM PCR profiling; ID, sample number; $P$, positive; $R$, resistant.

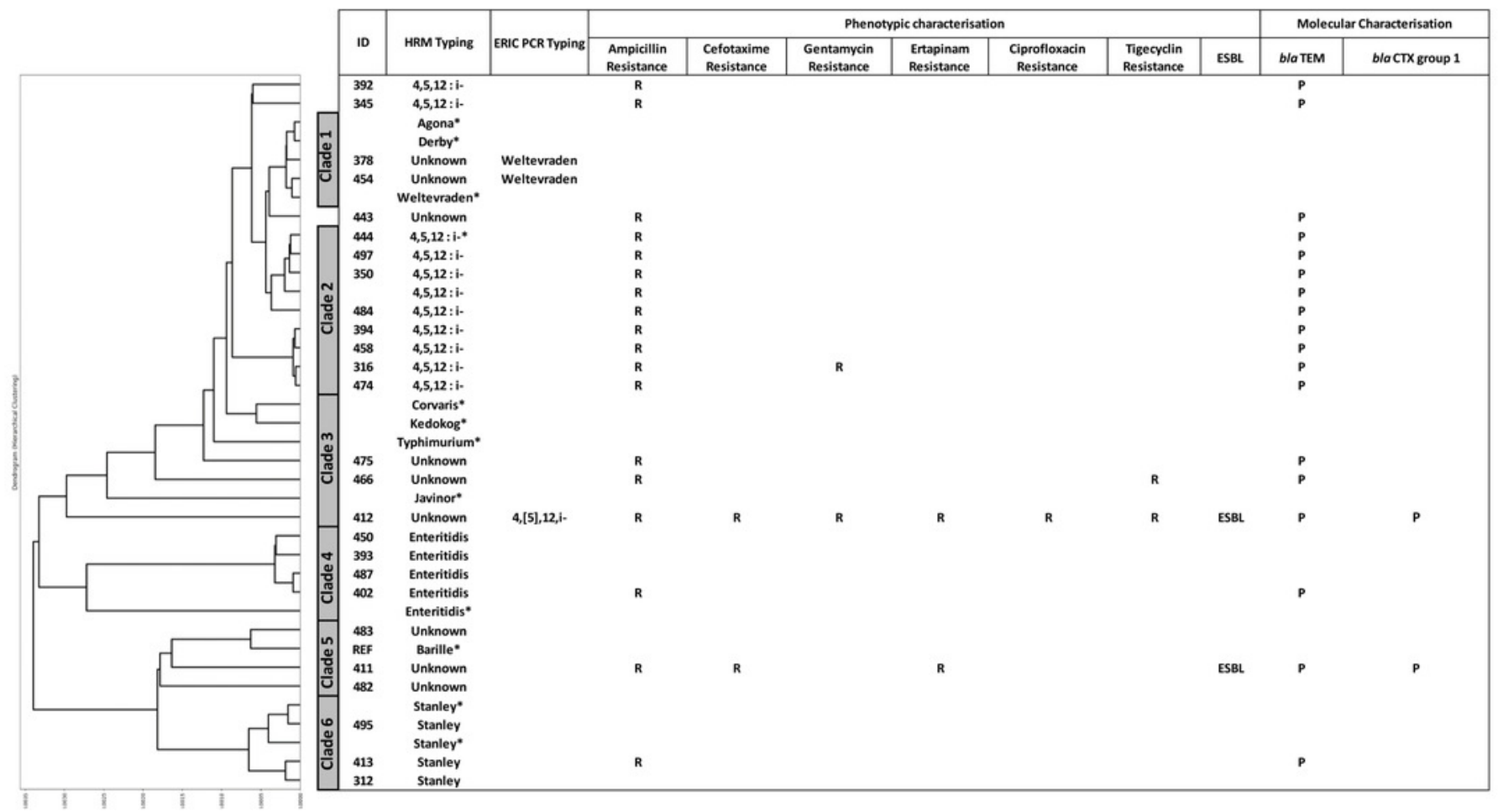




\section{Figure 4}

Gel electrophoresis of CRISPR 2 uniplex PCR amplicons of Salmonella isolates of ( $n=$ 26) from diarrheal patients stools, Phayao Ram Hospital, Phayao province, Thailand (2016-2017).

Uniplex PCR was performed using primers listed in Table 1. Number indicates sample ID. Name/number in box indicates Salmonella isolate of known serotype. marker, DNA size markers.

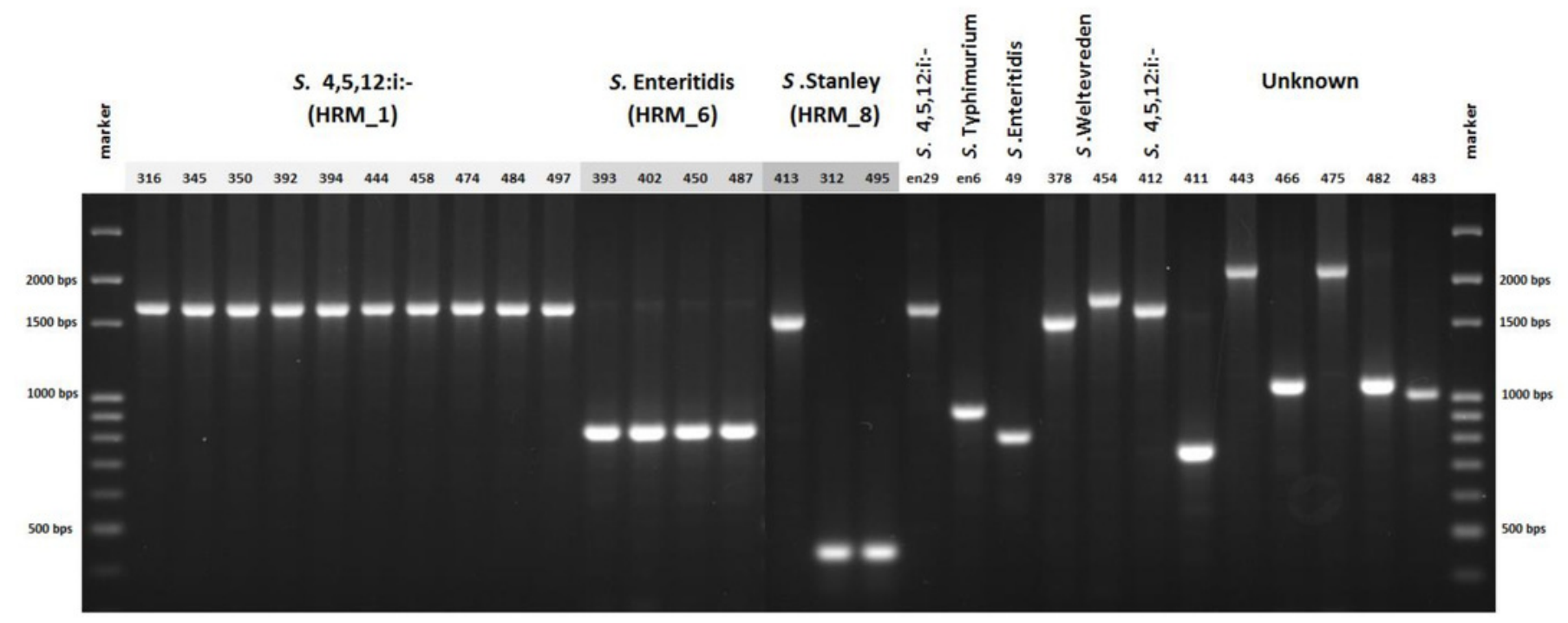




\section{Figure 5}

High resolution melting temperature-shifted difference profiles of CRISPR 2 uniplex amplicons of Salmonella isolates from diarrheal patients stools, Phayao Ram Hospital, Phayao province, Thailand (2016-2017).

Temperature-shifted difference melting profiles relative to (A) S. Agona and (B) S. 4,5,12:iM76 were generated using a BIO-RAD CFX96TM Real-Time System (Bio-Rad, Hercules, CA, USA). In (A), S. Typhimurium samples ( $n=5$ ) were from known stocks; in (B) S. 4,5,12:isamples included clinical samples from this study $(n=11)$, other human samples $(n=9)$ and pork meat $(n=4)$ (see Table 2). EN 8, S. 4,5,12:i- isolate from minced pork; RFU, relative fluorescence unit. 


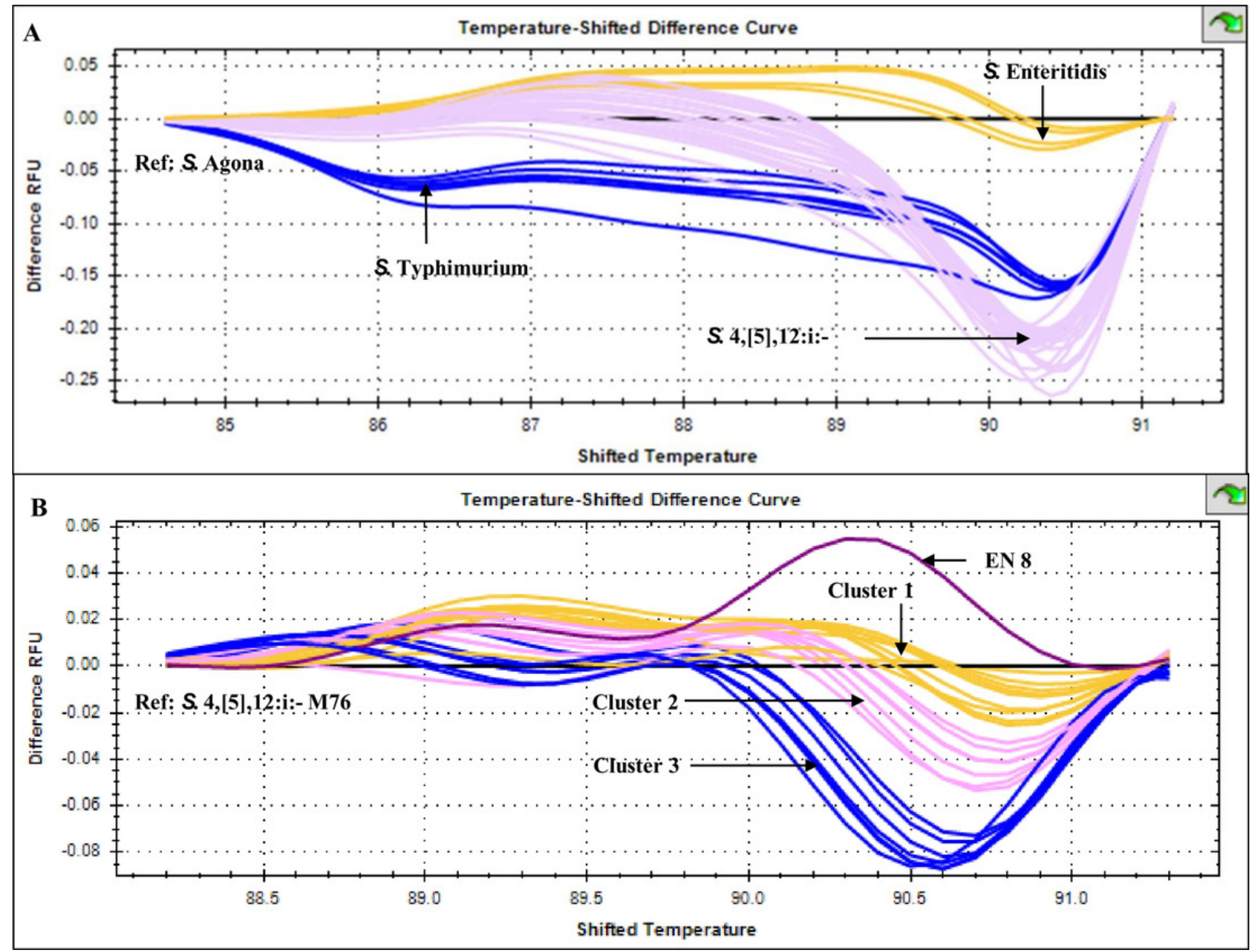




\section{Figure 6}

Seasonal variation of Salmonella isolates from diarrheal patients $(n=64)$ admitted to Phayao Ram Hospital, Phayao province, Thailand (April 2015- July 2017).

$\mathrm{Y}$-axis indicates cumulative number of cases in a given month. Serotype was determined using multiplex high resolution melting PCR profiling.

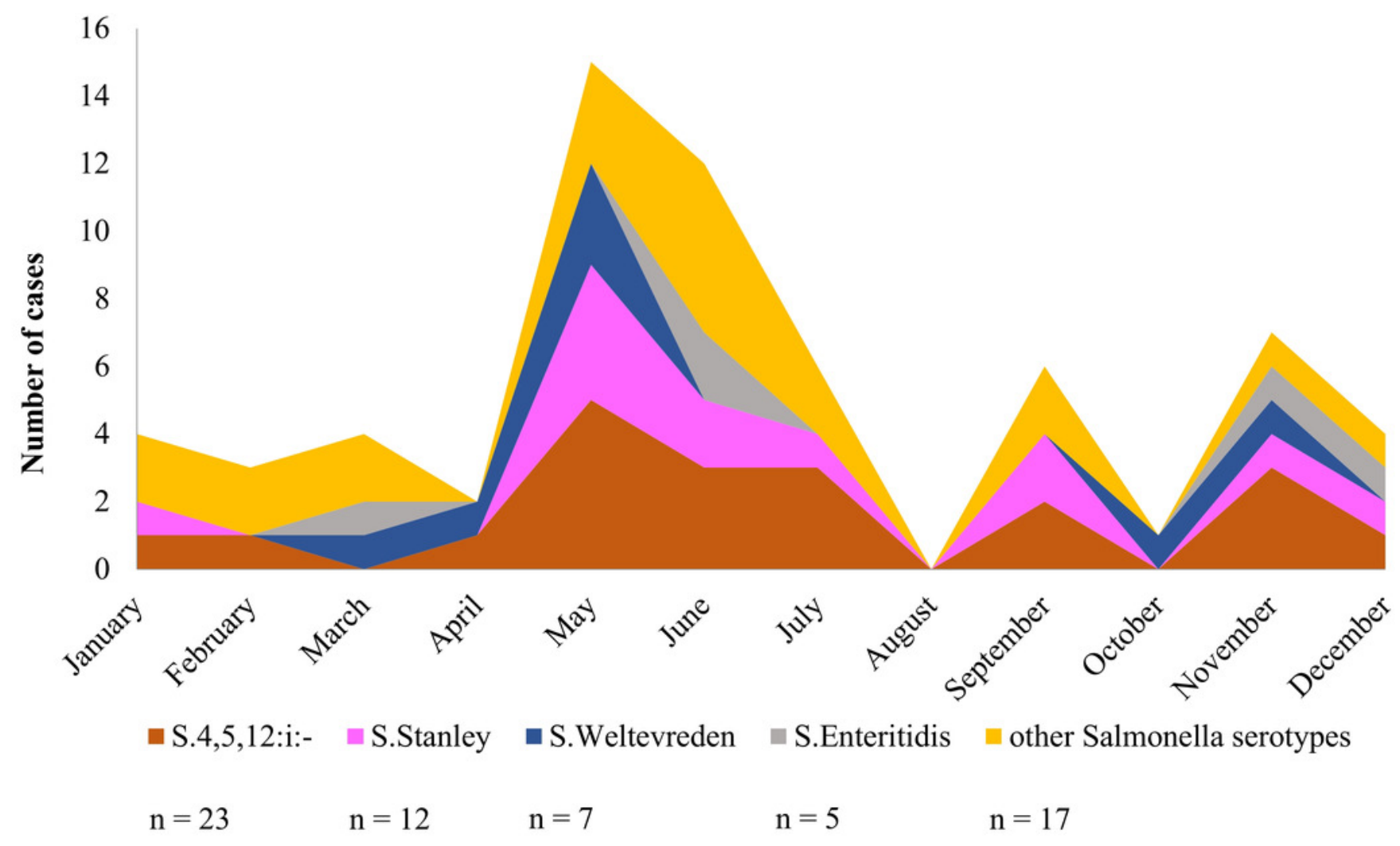

